Research Article

\title{
Awareness on Sexual Abuse among Adolescents in Baglung District of Nepal
}

\author{
Anita Sharma, \\ Kamala Rana Magar* \\ TU IOM, Pokhara Campus, Nepal, \\ Article History
}

Received 14 March, $2018 \quad$ Revised 12 September $2018 \quad$ Accepted 30 November 2018

\begin{abstract}
Sexual abuse is a pervasive public health problem that affects all directly or indirectly causing many short- and long-term struggles for victims, families, communities and the whole social system. Although sexual abuse is growing as a major problem in community, especially among the adolescents the trend and facts have not been explored adequately. Therefore, a descriptive study entitled "Awareness on Sexual Abuse among Adolescents" was carried out among 114 students of grade 9 and 10 in Tribhuvan Secondary School at Baglung Municipality. Census method was adopted and self-administered structured questionnaire was used for data collection. Data was analyzed using SPSS Version 16. Descriptive and inferential statistics were used to analyze the data. The findings revealed, almost 51 percent had low level of awareness on sexual abuse, and prevalence rate of sexual abuse was 18.4 percent. Out of 114 respondents, 38.6 percent were of age 14 years and 66.7 percent of the respondents were studying in grade 10 . The highest proportion 38.6 percent were Brahmin and 71.0 percent got information about sexual abuse from their teachers. More than half (59.6\%) respondents define try to rape as a sexual abuse. There was significant association between education of respondents with awareness on sexual abuse. It is concluded that the awareness on sexual abuse is low among adolescents therefore there is need of awareness program and education to adolescents in the school and community for improving their knowled ge as well as to make them aware of sexual abuse.
\end{abstract}

Key words: Abuse, adolescent, awareness, prevalence, sexual abuse awareness, sexual abuse

(C) 2018 The authors. Published by JRCC, Janapriya Multiple Campus

ISSN 2362-1516

Corresponding author*

Email: rana_kamala99@yahoo.com

\section{Introduction}

Child sexual abuse is the involvement of a child in sexual activity that he or she does not fully comprehend, is unable to give informed consent to, or for which the child is not developmentally 
prepared and cannot give consent, or that violates the laws or social taboos of society. Child sexual abuse is evidenced by this activity between a child and an adult or another child who by age or development is in a relationship of responsibility, trust or power, the activity being intended to gratify or satisfy the needs of the other person. WHO (World Health Organization) state that that female sex, unaccompanied children, children in foster care, adopted children, stepchildren, physically or mentally handicapped children, history of past abuse, poverty, war/armed conflict, psychological or cognitive vulnerability, single parent homes/broken homes, social isolation, parent(s) with mental illness, or alcohol or drug dependency are the risk factor for the victim of sexual abuse" (WHO, 1996).

Child sexual abuse is a global problem with serious life-long consequences. International studies reveal that a quarter of all adults' report have been physically abused as children and 1 in 5 women and 1 in 13 men report having been sexually abused as a child (WHO, 2016). There is very little knowledge about sexual abuse among adolescents. Adolescents get information about sexual abuse from school, mass media, friends and parents (Fouche, 2015). Adolescents are not so aware about sexual abuse and whoever are aware; many know about the harassment only after they have been into those situations (Desouky \& Marawan, 2013).

High school students with 11 to 20 years responded that they experienced physical abuse where aggressors were neighbors, strangers and relatives (Lucatero, Hernandez, Guerrero \& Vasquez, 2009). Different literature revealed that sexual abuse is one of the sensitive and growing problems of children especially of adolescents. In majority of the cases perpetrators are relatives and known person which might be difficult to recognize the victims that they are going to be abused. Impact of sexual abuse are unpredictable as suicidal thought is the effect of sexual abuse. Many study revealed that the level of knowledge/awareness about sexual abuse among adolescents was not good. Therefore, it is a necessary to assess awareness on sexual abuse among adolescents.

\section{Data and Methods}

A descriptive cross-sectional research design was conducted to assess the level of awareness on sexual abuse among adolescents. The study was done in Tribhuvan Secondary School, Baglung 
ward no 13 which is 15 kilometers northwest from Baglung city. Convenience Sampling was done to choose this school for the study. This is one of the oldest and well-known government school of Baglung established in 2007 B.S. Most of the adolescents in that area were enrolled in this school so; this school was selected for the study. The total adolescents who study in grade 9 and 10 were taken for the study. Total number of students in grade $9 \& 10$ were 114 students. Complete enumeration was technique was used and all adolescents were enrolled in the study.

Total population of the school is 450 . The population of the study was the adolescents who study in grade 9 and 10. All 114 students were enrolled in the study. A self-administered questionnaire schedule was developed to collect data on the basis of objectives of the study. It consists of two parts with total 24 questions. Part I consists of questions related to demographic information of the respondents and Part II consists of questions related to awareness on sexual abuse along with 5 questions regarding the experience of sexual abuse.

Tool was finalized on the basis of objectives of the study. Content validity of the tool was ascertained by consultation with colleagues, research advisors, faculties and subject experts. Pretesting of the tool was done in school children similar in setting to assess the clarity, feasibility and appropriateness of tool among 12 (10\% of the sample) students of class 9and 10 (6 from each class) in Shree Nava Prabhat Secondary School, Pokhara. Necessary modification was done after pretesting in order to ascertain the relevancy, consistency and completeness of instrument.

Data was collected after getting approval from T.U. I.O.M. Pokhara Campus and formal permission from Tribhuvan Secondary School. The objectives of the study were clearly stated and explained to each respondent. They were clearly explained about their voluntary participation in the study and they were free to refuse to participate in research. Informed verbal consent was taken from the respondents. Then self-administered questionnaire were distributed to the respondents that were collected on the same day by the researcher herself. Time duration for each respondent was 15-20 minutes. Data was collected from 2074/02/21-2074/03/02. Confidentiality was assured by not disclosing the information given by respondents and it was explained to them. 
Data was arranged and tabulated in computer to present the findings and was analyzed and interpreted by employing both descriptive (frequency, percentage, mean and standard deviation) and inferential statistical method (Chi-square test). The level of significance was set as $5 \%$ with $p$ value $<0.05$ and $95 \%$ confidence interval. Regarding knowledge, each of the correct answer was given the weightage score 1 . The level of awareness was calculated by using mean value of total awareness. The level of awareness was categorized in low level, average level and high level awareness (Jasmine \& Hamed, 2016).

\section{Results and Discussion}

\section{Table 1}

Respondents Classified According to Selected Background Characteristics

\begin{tabular}{|c|c|c|}
\hline Characteristics & Number & Percentage \\
\hline \multicolumn{3}{|l|}{ Age (in years) } \\
\hline 13 & 13 & 11.4 \\
\hline 14 & 44 & 38.6 \\
\hline 15 & 32 & 28.1 \\
\hline 16 & 25 & 21.9 \\
\hline \multicolumn{3}{|l|}{ Mean \pm SD $14.60 \pm 0.95$} \\
\hline \multicolumn{3}{|l|}{ Gender } \\
\hline Male & 52 & 45.6 \\
\hline Female & 62 & 54.4 \\
\hline \multicolumn{3}{|l|}{ Current grade of class } \\
\hline Grade 9 & 38 & 33.3 \\
\hline Grade 10 & 76 & 66.7 \\
\hline \multicolumn{3}{|l|}{ Ethnicity } \\
\hline Brahmin & 44 & 38.6 \\
\hline Chhetri & 19 & 16.7 \\
\hline Janajati & 08 & 7.0 \\
\hline Dalit & 43 & 37.7 \\
\hline \multicolumn{3}{|l|}{ Family Type } \\
\hline Monogamous & 107 & 93.9 \\
\hline Polygamous & 05 & 4.4 \\
\hline Single parents & 02 & 1.8 \\
\hline \multicolumn{3}{|l|}{ Father's Education } \\
\hline Illiterate & 09 & 7.9 \\
\hline Can read and write & 23 & 20.2 \\
\hline Primary level & 15 & 13.1 \\
\hline Secondary level & 35 & 30.7 \\
\hline Higher education & 32 & 28.1 \\
\hline Mother's education & & \\
\hline
\end{tabular}




\begin{tabular}{lcc}
\hline Illiterate & 15 & 13.2 \\
Can read and write & 22 & 19.2 \\
Primary level & 24 & 21.1 \\
Secondary level & 41 & 36.0 \\
Higher education & 12 & 10.5 \\
Source* & & \\
Teacher & 81 & 71.1 \\
Parents & 26 & 22.8 \\
Other family member & 19 & 16.7 \\
Friends & 30 & 26.3 \\
Mass media & 73 & 64.0 \\
\hline
\end{tabular}

Note: *multiple responses

Source: Field survey 2074

Table 1 shows that 44.0 percent of the respondents belonged to age 14 years and the mean age was 14.6 years. Almost 55.0 percent of respondents were female with 38.6 percent of respondents belonged to age group 14. The mean age was 14.60 years (standard deviation \pm 0.95years) and 66.7 percent of the respondents were of grade 10. The highest proportions 38.6 percent of the respondents were Brahmin and most $(93.9 \%)$ of the respondents belonged to monogamous family. The study showed that 30.7 percent of the respondents' fathers' and 36.0 percent of the respondents' mothers' education was secondary level. From teacher 71.1 percent of respondents got information about sexual abuse.

Table 2

Awareness on Sexual Abuse among Respondents

\begin{tabular}{lcc}
\hline Characteristics & Number & Percentage \\
\hline Meaning of sexual abuse* & & \\
Shown porno graphic materials & 39 & 34.2 \\
Touch or catch others, private body parts & 43 & 37.7 \\
Try to see naked/ private parts & 46 & 40.4 \\
Use of vulgar wards & 48 & 42.1 \\
Rape & 62 & 54.4 \\
Expose own private part by perpetrator & 63 & 53.3 \\
Try to rape & 68 & 59.6 \\
Knowledge about law & & \\
Perpetrator should be punish & 112 & 98.2 \\
There is law against sexual abuse & 76 & 66.7 \\
Victim of sexual abuse & & \\
Children & 02 & 1.8 \\
Preteens & 07 & 8.1 \\
Adolescents & 93 & \\
\hline
\end{tabular}




\begin{tabular}{lcc}
\hline Youth & 12 & 10.5 \\
Gender of victim & & \\
Boys only & 01 & 0.9 \\
Girls only & 28 & 24.5 \\
Both boys and girls & 85 & 74.6 \\
Place of sexual abuse* & & \\
School & 10 & 8.8 \\
Home & 15 & 13.2 \\
Work place & 42 & 36.8 \\
Public place & 93 & 81.6 \\
\hline
\end{tabular}

*Multiple response

Source: Field survey 2074

Table 2 reveals that 59.9 percent of the respondents defined sexual abuse as try to rape. It was found that 66.7 percent were known about the law against sexual abuse in Nepal and most (98.2\%) of respondents stated that the perpetrator should be punished. Regarding the knowledge about the victim of sexual abuse 81.6 percent respondents answered as adolescents where 74.6 percent mentioned both boys and girls can be the victim of sexual abuse. Eighty one percent of respondents indicated public place as a place for sexual abuse.

Table 3

Awareness on Consequences and Approach to Stop Sexual Abuse

\begin{tabular}{lcc}
\hline Characteristics & Number & Percentage \\
\hline Reason behind sexual abuse * & & \\
Overcrowded households & 06 & 5.3 \\
Thinking lowly of own self & 11 & 9.6 \\
Living with single parents & 12 & 10.5 \\
No friend support & 14 & 12.3 \\
Living with step parents & 22 & 19.3 \\
Parents don't talk about sexual abuse & 35 & 30.7 \\
No sexual education & 44 & 38.6 \\
Pressure from friends & 45 & 39.5 \\
Dress up & 48 & 42.1 \\
Bad family relationship & 55 & 48.2 \\
No discipline in home & 55 & 48.2 \\
Drinking a lot of alcohol & 70 & 61.4 \\
Taking drugs & 93 & 81.6 \\
Consequences of sexual abuse $*$ & & \\
Eating disorder & 19 & 16.7 \\
\hline
\end{tabular}




\begin{tabular}{lcc}
\hline Sleeping disorder & 21 & 18.4 \\
Depression & 30 & 26.3 \\
Anxiety & 62 & 54.4 \\
Phobia & 73 & 64.0 \\
Suicidal thoughts & 84 & 73.7 \\
Best approach for sharing information* & & \\
$\quad$ Information pamphlets & 24 & 21.1 \\
Showing documentary & 44 & 38.6 \\
Education & 63 & 55.3 \\
Website information & 69 & 60.5 \\
Best approach for stop sexual abuse * & & \\
Education & 47 & 41.2 \\
Awareness program & 71 & 62.3 \\
Strong law & 77 & 67.5 \\
\hline
\end{tabular}

Note: *Multiple response

Source: Field survey 2074

Table 3 shows that total 81.6 percent respondents stated that the using drugs can cause sexual abuse and 73.7 percent mentioned suicidal thought as a consequence of sexual abuse. Sixty percent indicated that website is the best way to share information and 67.5 percent of respondents mentioned strong law is the best approach to stop sexual abuse.

Table 4

Respondent's Experience of Sexual Abuse

\begin{tabular}{lcc}
\hline Characteristics & Number & Percentage \\
\hline Types of abuse faced* & & \\
Try to see naked/private parts & 01 & 4.8 \\
Touch or catch other body parts & 03 & 14.3 \\
Perpetrator expose own private part & 04 & 19.0 \\
Try to rape & 04 & 19.0 \\
Shown pornographic materials & 05 & 23.8 \\
Use of vulgar words & 14 & 66.7 \\
Frequency of event & & \\
Rarely & 01 & 4.8 \\
Frequently & 04 & 19.0 \\
Only once & 16 & 76.2 \\
Perpetrator & & \\
Teacher & 01 & 4.8 \\
Relatives & 02 & 9.5 \\
Stranger & 04 & 19.0 \\
Friends & 05 & 23.8 \\
Lover & 09 & 42.9 \\
\hline
\end{tabular}




\begin{tabular}{lll}
\hline Sex of perpetrator & & \\
Female & 10 & 47.6 \\
Male & 11 & 52.4 \\
\hline
\end{tabular}

Note: $*$ Multiple response

Source: Field survey 2074

Table 4 shows that among 114 respondents, total of 21 adolescents were exposed to sexual abuse. Among them 66.7 percent of respondents experienced the use of vulgar word as a sexual abuse and 76.2 percent experience for only one time. Forty three percent of perpetrators were lover among whom 52.4 percent were male.

Table 5

\begin{tabular}{lcc} 
Level of Awareness on Sexual Abuse & $(n=114)$ \\
\hline Level of Awareness & Number & Percentage \\
\hline Low level & 58 & 50.9 \\
Average level & 06 & 05.3 \\
High level & 50 & 43.9 \\
\hline
\end{tabular}

Note: The level of awareness was calculated by using mean value of total awareness (Jasmine $\&$ Hamed, 2016). The minimum score of awareness is 12 and maximum score is 40 . Mean value is 21.94 and Std. Deviation \pm 5.525 .

Source: Field survey 2074

Table 6 Association Between Level of Awareness on Sexual Abuse With Selected Variables $(n=114)$

\begin{tabular}{|c|c|c|c|c|c|}
\hline \multirow[t]{2}{*}{ Variables } & \multicolumn{2}{|c|}{ Level of Awareness } & \multirow[b]{2}{*}{$\chi^{2}$} & \multirow[b]{2}{*}{ (df) } & \multirow[b]{2}{*}{$p$-value } \\
\hline & High level & Low level & & & \\
\hline & $\mathrm{n}(\%)$ & $\mathrm{n}(\%)$ & & & \\
\hline \multicolumn{6}{|l|}{ Age(in years) } \\
\hline $13-14$ & $27(47.4)$ & $30(52.6)$ & 0.140 & 1 & 0.708 \\
\hline $15-16$ & $29(50.9)$ & $28(49.1)$ & & & \\
\hline \multicolumn{6}{|l|}{ Gender } \\
\hline Male & $25(47.2)$ & $28(52.8)$ & 0.151 & 1 & 0.697 \\
\hline Female & $31(50.8)$ & $30(49.2)$ & & & \\
\hline \multicolumn{6}{|l|}{ Education } \\
\hline Class 9 & $13(23.2)$ & $25(43.1)$ & 5.052 & 1 & 0.024 \\
\hline Class10 & $43(76.8)$ & $33(56.9)$ & & & \\
\hline \multicolumn{6}{|c|}{ Past experience } \\
\hline Yes & 13(61.9) & $8(38.1)$ & 1.683 & 1 & 0.195 \\
\hline No & $43(46.2)$ & $50(53.8)$ & & & \\
\hline \multicolumn{6}{|c|}{ Father's education } \\
\hline Illiterate & $14(43.8)$ & $18(56.3)$ & 0.514 & 1 & 0.473 \\
\hline Literate & $42(51.2)$ & $40(48.8)$ & & & \\
\hline
\end{tabular}




\begin{tabular}{llllll}
\hline Mother's education & & & & \\
Illiterate & $18(48.6)$ & $19(51.4)$ & 0.005 & 1 & 0.94 \\
Literate & $38(49.4)$ & $39(50.6)$ & & & \\
\hline
\end{tabular}

Source: Field survey 2074

Table 6 shows, there is significant association between the education of respondents with awareness $(p<0.05)$ but it is revealed that there is no significant association between level of awareness on sexual abuse with age, gender, past experience and parents' education.

\section{Discussion}

The present study showed 54.4 percent of respondents were female with 38.6 percent of respondents belonged to age group 14. The mean age was 14.60 years (standard deviation \pm 0.95years) and 66.7 percent of the respondents were of grade 10. The highest proportions 38.6 percent of the respondents were Brahmin and most (93.9\%) of the respondents belonged to monogamous family. The study showed that 30.7 percent of the respondents' fathers' and 36.0 percent of the respondents' mothers' education was secondary level. This study revealed that the major sources of information on sexual abuse were teachers in 71.1 percent of respondents which is consistent to the findings of previous the study (Nlewem \& Amodu, 2016; Fouche, 2015).

In the present study, high level of awareness was seen in 43.9 percent, average level awareness in 5.2 percent and low-level awareness in 50.9 percent. The level of awareness score is dissimilar to the findings of a previous study where good knowledge seen in 27 percent average knowledge in 62 percent and 11 percent with poor knowledge (Anusha et al., 2015).

In this study 59.6 percent of the respondents defined sexual abuse as try to rape and 54.4 percent of them perceived sexual abuse as an expose of private part by perpetrator. This response is similar to the study done in Abia State Nigeria (Nlewem \& Amodu, 2016).

The study mentioned that 66.7 percent were known about the law against sexual abuse in Nepal and most $(98.2 \%)$ of respondents stated that the perpetrator should be punished which is consistent to another study done at Chennai (Joshe, 2015).

Regarding the knowledge about the victim of sexual abuse 81.6 percent respondents answered as adolescents which is supported by a study conducted at rural area of the Northern Cape (Fouche, 2015) while 74.6 percent mentioned both boys and girls can be the victim of sexual abuse which 
is similar to the study revealing that girls are not only victim of sexual abuse (Dzimadzi \& Klopper, 2007).

Eighty-one percentage of respondents indicated public place as a place for sexual abuse this finding is consistence to the study of Menoufiya University (Desouky \& Marawan, 2013) and inconsistent to study where the higher number of respondents responded home as a place of sexual abuse (Jasmid \& Hameed, 2016). Regarding the reason behind sexual abuse 81.6 percent stated the use of drug which is consistent to the study conducted at rural area of Northern Cape (Fouche, 2015).

Present study revealed that 73.7 percent mentioned suicidal thought as a consequence of sexual abuse which is inconsistence to the finding of study done at Minnisota University showing anxiety (Muse, 2013). Sixty percent respondents indicated that website is the best way to share information and 67.5 percent mentioned strong law is the best approach to stop sexual abuse. This finding is the similar to the study done in rural area of Northern Cape (Fouche, 2015).

In concerning the prevalence of sexual abuse was 18.42 percent which is consistent to the previous research study (Lucatero, et al., 2009; Joshe, 2015). In this study 66.7 percent respondents experienced the use of vulgar word, faced the exposure of pornographic materials which is consistence to the study done at Tirunelvelli district (Pavithra \& Relton, 2017).

Present study mentioned that 76.2 percent experienced sexual abuse for only one time which is similar to the study with finding the length of the time of sexual abuse lasted were one time only (Lucatero, et al., 2009). The study showed 42.9 percent of perpetrator were lover and the 52.4 percent of perpetrator were male which is consistence to another study done by Dzimadzi \& Klopper, (2007).

There is significant association between the education of respondents with awareness on sexual abuse $(p<0.05)$ but not with age, gender, past experience and parent education. This finding is inconsistent to the study done at Punjab (Kaur, 2017). There is no significant association between level of awareness among experienced and non-experienced respondents which is similar to another study (Dzimadzi \& K lopper, 2007).

\section{Conclusion}


The study concluded that half of the respondents have low level of awareness on sexual abuse and there is significant association between the education of respondents with awareness. On the basis of finding on awareness level it is needed to provide awareness program to respondents regarding sexual abuse.

\section{Acknowledgement}

I would like to appreciate all the helping hand behind this study. I acknowledge unwavering support and tireless effort by thesis advisor (Kamala Rana Magar), faculties of Pokhara Campus, Institute of Medicine, including Professor Dr. Vikash Kumar K.C for valuable statistical guidance, librarian and management authority, Principal and students of Tribhuvan Secondary School.

\section{References}

Anusha, U. K., Saraswathi, K. N., Nair, N. P., \& Williams, S. (2015). A study to Assess the Knowledge regarding Sexual Abuse among Adolescent Girls in selected High Schools at Mysuru. International Journal of Nursing Education and Research, 3(3), 294-298.

Douskey, D. E.-S., \& Marawan, H. (2013). Awareness and Experience of Sexual Harassment among Menoufiya University Students. Asia Journal of Public Health, 4, 16-26.

Dzimadzi, R., \& Klopper, H. (2007). Knowled ge of sexual abuse amongst female students in Malawi. Curationis, 30 (3), 23-30.

Fouché, J. M. (2015). Adolescents' knowledge and awareness re garding sexual abuse in a rural area of the Northern Cape. Doctoral dissertation, North-West University (South Africa), Potchefstroom Campus, 12, 24-27.

Jasmine, K. \& Hameed, A. (2016). Child Abuse Awareness among Higher Secondary School Students. Journal of Research \& Method in Education, 6(4), 75-79. Joshe.k, U. (2015). A Study on The Awareness on Sexual Abuse Among Girls in Chennai Schools. Indian Journal of Applied Research, 5 (9), 252-254. 
Pineda-Lucatero, A. G., Trujillo-Hernández, B., Millán-Guerrero, R. O., \& Vásquez, C. (2009). Prevalence of childhood sexual abuse among Mexican adolescents. Child: care, health and development, 35 (2), 184-189.

Muse, F. A. (2013). Selected College Students' Perceptions, Knowledge and Awareness of Sexual Abuse of Children.

Nlewem, C. \& Amodu, O. (2016). Knowledge and Perception on Sexual Abuse Amongst Female Secondary School Students in Abia State Nigeria. Research on Humanities and Social Science, 6 (17), 74-84.

Pavithra, R. \& Relton, A. (2017). Sexual Abuse among Adolescent School Girls in Tirunelvelli District. IOSR Journal of Humanities and Social Science (IOSR-JHSS), 1 (12), 58-62.

World Health Organization. (2016). Child maltreatment. Retrieved from http://www.who.int/mediacentre/factsheets/fs150/en/ on 2017/05/07 